\title{
LINEAR AND VOLUMETRIC ASSESSMENT OF THE MAXILLARY SINUS
}

\author{
Tihomir Georgiev ${ }^{1}$, Karen Djabalian¹, Radosveta Andreeva ${ }^{2}$, Krasimira Prodanova $^{3}$ \\ ${ }^{1}$ Department of Oral and Maxillofacial Surgery, Faculty of Dental Medicine, \\ Medical University of Varna \\ ${ }^{2}$ Department of Pediatric Dental Medicine, Faculty of Dental Medicine, \\ Medical University of Varna \\ ${ }^{3}$ Department of Statistics and Optimizations, Technical University of Sofia
}

\begin{abstract}
INTRODUCTION: Pneumatization of the maxillary sinus can be triggered throughout a patient's life. Prior to any sinus floor augmentation procedure, it is imperative to conduct a linear and volumetric assessment of the maxillary sinus.

MATERIALS AND METHODS: The CBCT scans in this randomized retrospective study were selected from 120 patients ( 50 men and 70 women) to analyze the maxillary sinus dimensions both linearly and volumetrically.

RESULTS: The volume of the maxillary sinus was significantly increased in the male patients. Statistically significant differences in the volume of the maxillary sinuses were not observed in dentate or edentulous patients.
\end{abstract}

CONCLUSIONS: CBCT imaging for surgical interventions of the maxillary sinus to assess its volume and size has proven to be an indispensable diagnostic tool.

Keywords: maxillary bone volume, deficiency, atrophy, resorption, volumetric measurements, sinus lift, sinus pneumatization, CBCT

Address for correspondence:

Tihomir Georgiev

Faculty of Dental Medicine

Medical University of Varna

84 Tzar Osvoboditel Blvd.

9000 Varna, Bulgaria

e-mail: tgeorgievphd@yahoo.com

Received: May 25, 2016

Accepted: June 24, 2016

\section{INTRODUCTION}

The volume of the maxillary sinus and its pneumatization are essential for the oral surgeon, particularly in the cases of extraction of the maxillary posterior teeth, dental implant placement or maxillary sinus floor elevation. In those interventions the volume of the maxillary sinus may affect the clinical outcome of the procedure where failure to assess the volume may give rise to a number of complications. Teeth extraction (1) hides the risk of oroantral communications $(2,3)$, root tip loss in the maxillary sinus (4), which in turn may result in inflammation in the maxillary sinus (5). With implant placement 
Tihomir Georgiev, Karen Djabalian, Radosveta Andreeva et al.

in the region of the maxillary molars, inaccurately measured volume of the residual bone can contribute to a migration of the implant in the maxillary sinus $(6,24)$, in the sphenoid sinus (7) as well as intraorbitally (8). With maxillary sinus floor augmentation procedures the lack of volumetric measurement can have clinical implications, such as difficulty in lifting the bone window using lateral access, insufficient bone graft for the surgery and subsequent failure of the implant placement in the exact prosthetic position (9).

\section{MATERIALS AND METHODS}

This retrospective study analyzed CBCT scans belonging to 120 patients selected randomly. Each patient, referred for a three-dimensional imaging at the University Medical Dental Center, signed an Informed Consent agreeing on the subsequent use of their scans for scientific research purposes. All images used in this study are of patients who have a planned dental implant placement in the maxilla. The scans were acquired with a cone-beam computed tomography scanner (Planmeca ProMax 3D Max), integrated with a computer hard drive and backup peripheral devices, software for reconstructing images (Planmeca Romexis) and a patients registration program. The scanning parameters were: scanning time - 9-40 sec., image reconstruction time - 2-55 sec. The CBCT images were stored and read by Planmeca Romexis software, compatible with Windows XP, Windows 7 and Windows 8.

The volume of each patient's maxillary sinus was carefully measured (Figure 1 and 3), along with its length (antroposterior dimension), the width (mediolateral dimension) (Figure 2) and the height (craniocaudal dimension) (Figure 1) of the maxillary si-

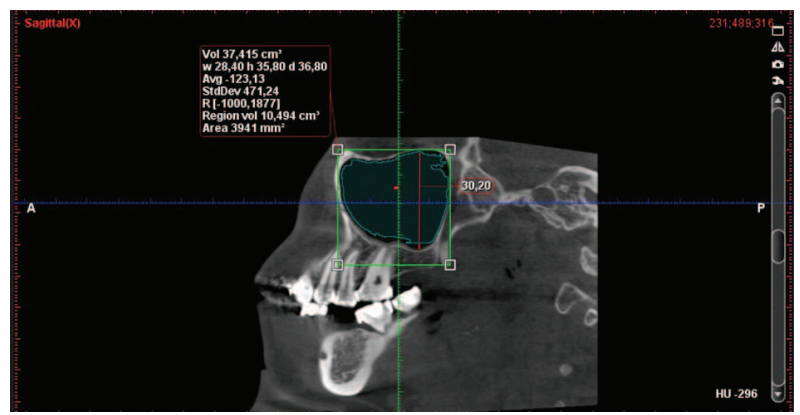

Fig. 1. Volumetric measurement of the maxillary sinus: $10.494 \mathrm{~cm}^{3}$ (regional volume); maxillary sinus height: $30.20 \mathrm{~mm}$

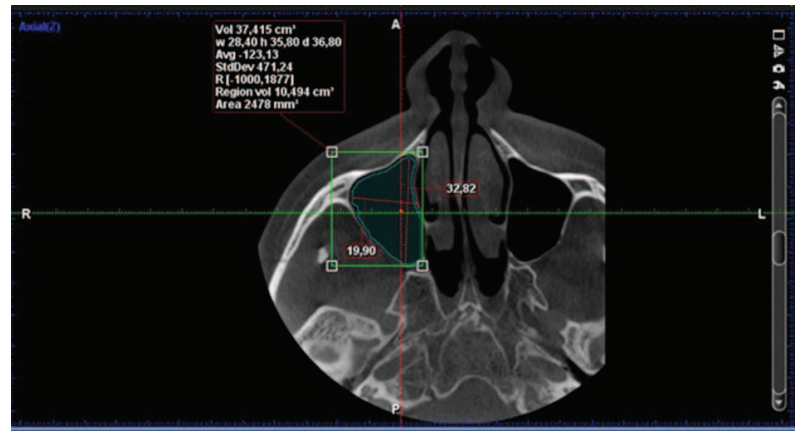

Fig. 2. Maxillary sinus length measurement (antroposterior dimension): $32.82 \mathrm{~mm}$; width measurement (mediolateral dimension): $19.90 \mathrm{~mm}$

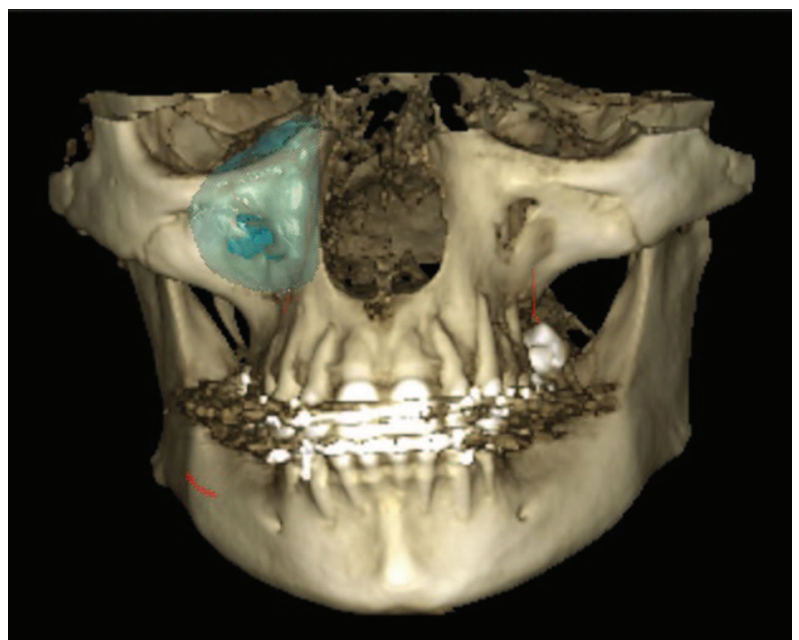

Fig. 3. The volume of the maxillary sinus in a three-dimensional reconstruction

nus. Statistically significant differences were assessed between genders as well as between sinuses with present contiguous teeth and edentulous distal regions of the maxilla.

The volumetric measurements are taken with the help of a software application which has the option to select and color the sinus cavity to be measured. In order to measure the length, width and height of the maxillary sinus we used the furthermost points located on the opposite walls. We then analyzed the correlation between all values for both genders as well as the relation between the maxillary sinuses with contiguous dentate and edentulous sites. Thus, based on the dimensional alterations, we evaluated the statistically significant difference between the secondary and primary pneumatization of the maxillary sinus. The target group excluded patients with mucosal 
reactions, such as thickening of the sinus membrane, pseudocysts, retention cysts, etc., as those conditions interfered with the program to accurately analyze the sinus volume by measuring only the air-filled area (Figure 4).

The analysis of the images was carried out by two lecturers at the University Medical Dental Clinic, performed independently. Any discrepancies in the parameters under study were consulted with a dental radiologist.

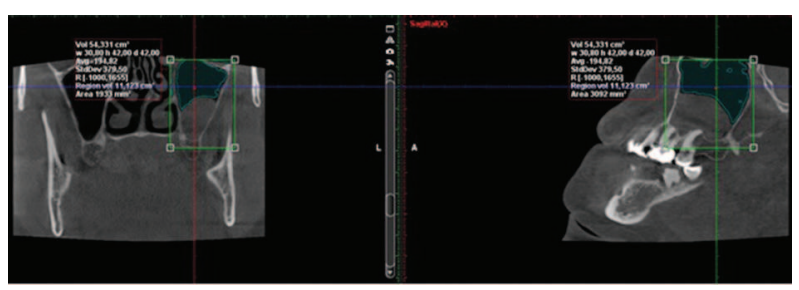

Fig. 4. A patient with significant thickening of the sinus mucosa, making it impossible to accurately measure the sinus volume

\section{RESULTS}

$120 \mathrm{CBCT}$ scans of maxillary sinuses were investigated, belonging to 70 patients (35 male and 85 female patients). 70 scans showed sinuses with present teeth beneath them, 50 scans revealed edentulous maxillary bone. The mean age was 48 years, ages ranging between 31 - 76 years.

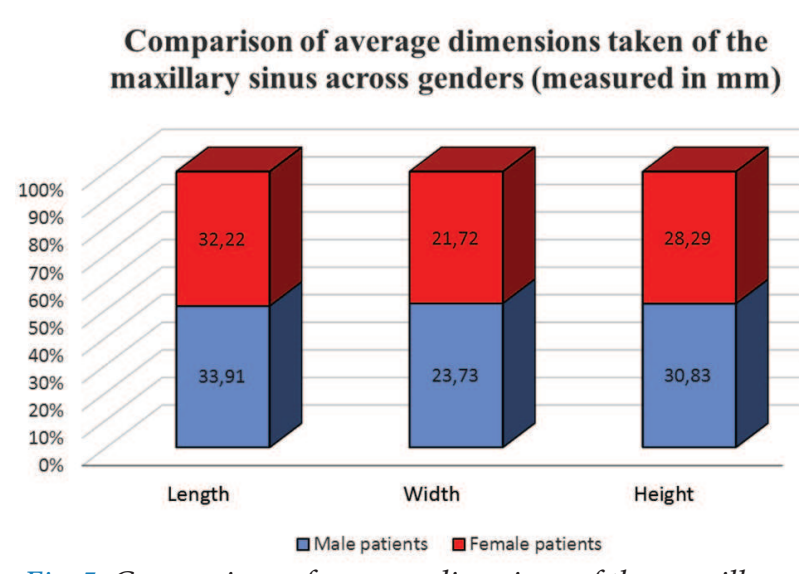

Fig. 5. Comparison of average dimesions of the maxillary sinus by gender

The average sinus volume was $14.080358 \mathrm{~cm}^{3}$, while the largest volume was $25.472 \mathrm{~cm}^{3}$ and the smallest one being $4.924 \mathrm{~cm}^{3}$.

The average length of the maxillary sinus was $32.71 \mathrm{~mm}$, while the largest measured length was $41.80 \mathrm{~mm}$ and the shortest one being 23.13 $\mathrm{mm}$. The average width of the maxillary sinus was $22.99 \mathrm{~mm}$, while the largest measured width was $32.22 \mathrm{~mm}$ and the shortest length being $14.20 \mathrm{~mm}$. The average height of the maxillary sinus was 29.03 $\mathrm{mm}$, while the highest value was $43.40 \mathrm{~mm}$ and the lowest one being $17.20 \mathrm{~mm}$. A statistically significant difference in the values related to the size of the max-

Tabl. 1. A significant height difference in male and female patients, the p-value being set at 0.0139 i.e. $<0.05$

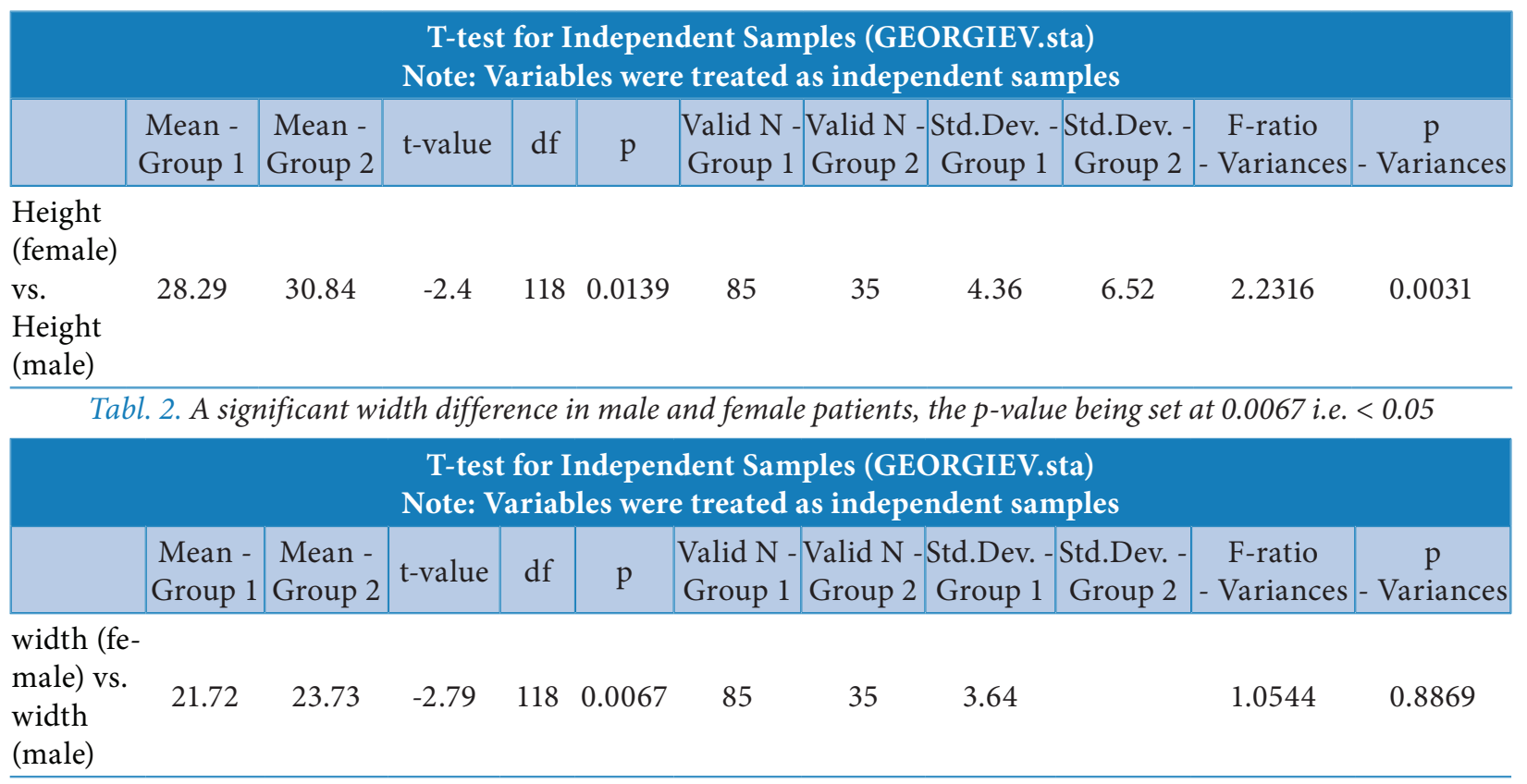


Tihomir Georgiev, Karen Djabalian, Radosveta Andreeva et al.

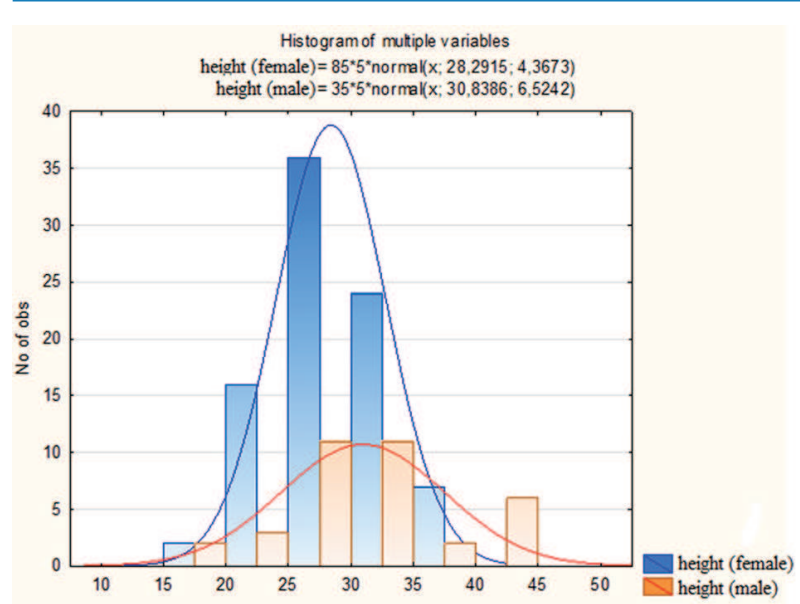

Fig. 6. A histogram demonstrating the comparison of height values of the maxillary sinus across genders

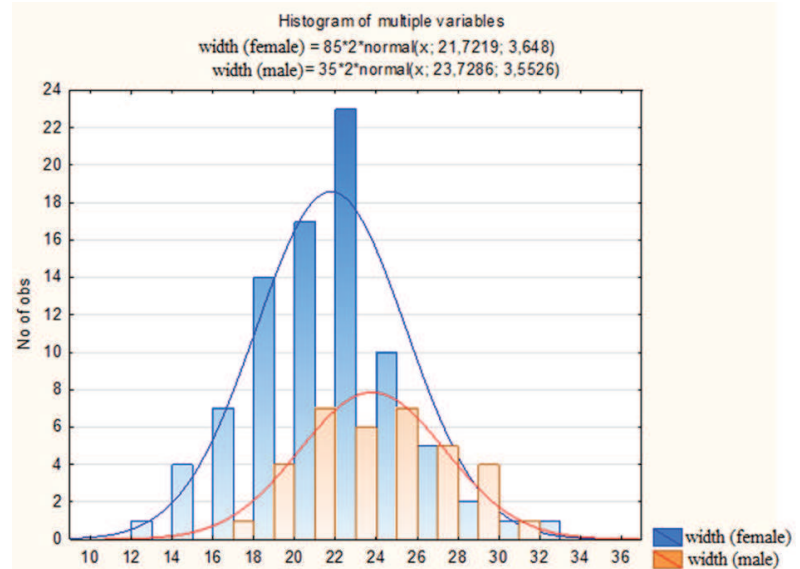

Fig. 7. A histogram demonstrating the comparison of width values of the maxillary sinus across genders

illary sinus was observed between genders (Figures 5-8, Tables 1-3).

Statistically significant differences were found in the volumetric measurements of the maxillary sinuses (Figures 9-10, Table 4).

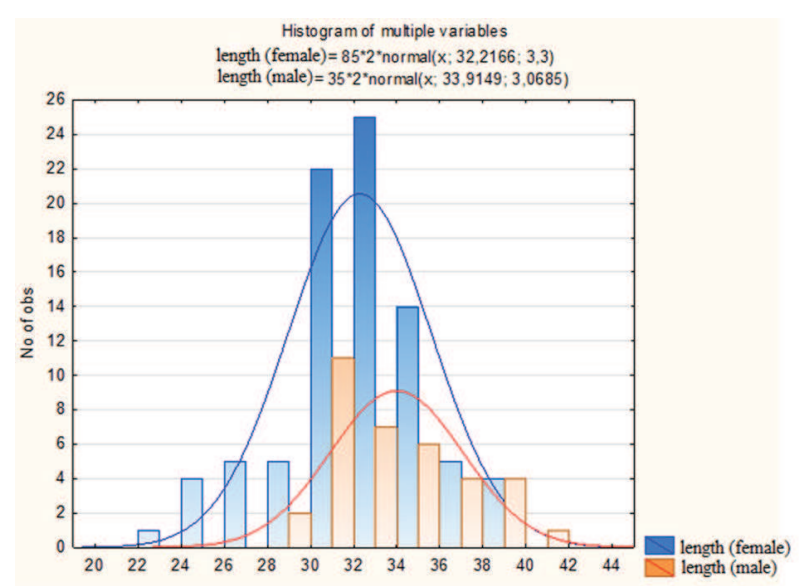

Fig. 8. A histogram demonstrating the comparison of length values of the maxillary sinus across genders

Comparison of volumetric measurements of the maxillary sinus across genders (measured in $\mathbf{~ c m}^{3}$ )

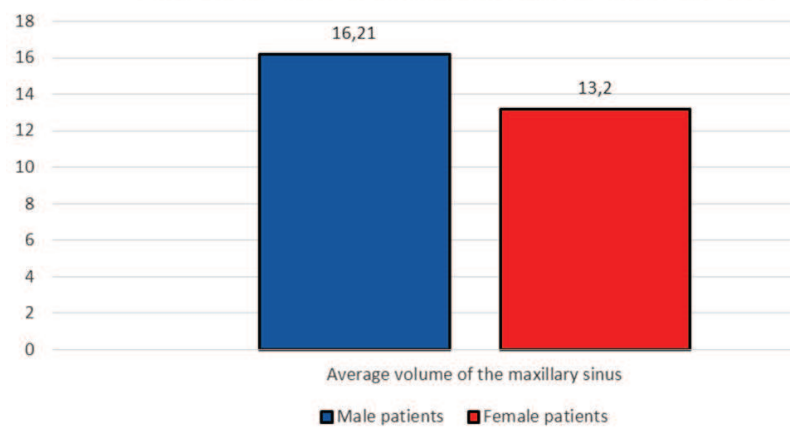

Fig. 9. Comparison of volumetric measurements of the maxillary sinus

Table 4 presents a t-test for the statistically significant difference between the average values of the volume of the maxillary sinus across genders.

A statistically significant difference was not observed comparing the volume, height, length and width of the maxillary cavity in patients with present

Tabl. 3. A significant length difference in male and female patients, the p-value being set at 0.0101 i.e. $<0.05$

\begin{tabular}{|c|c|c|c|c|c|c|c|c|c|c|c|}
\hline \multicolumn{12}{|c|}{$\begin{array}{l}\text { T-test for Independent Samples (GEORGIEV.sta) } \\
\text { Note: Variables were treated as independent samples }\end{array}$} \\
\hline & $\begin{array}{l}\text { Mean - } \\
\text { Group } 1\end{array}$ & $\begin{array}{l}\text { Mean - } \\
\text { Group } 2\end{array}$ & t-value & $\mathrm{df}$ & $\mathrm{p}$ & $\begin{array}{l}\text { Valid N } \\
\text { Group } 1\end{array}$ & - Valid N & $\begin{array}{l}\text { Std.Dev. - } \\
\text { Group } 1\end{array}$ & $\begin{array}{l}\text { Std.Dev. - } \\
\text { Group } 2\end{array}$ & $\begin{array}{c}\text { F-ratio } \\
\text { - Variances }\end{array}$ & $\stackrel{\mathrm{p}-}{\text { Variances }}$ \\
\hline \multicolumn{12}{|c|}{ 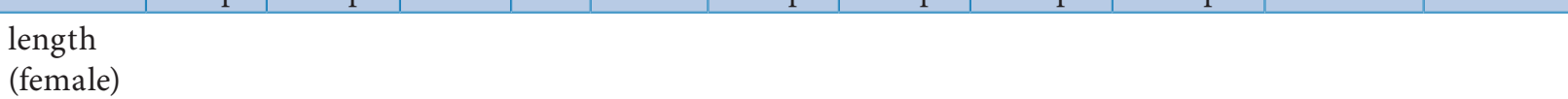 } \\
\hline $\begin{array}{l}\text { vs. } \\
\text { length } \\
\text { (male) }\end{array}$ & 32.22 & 33.92 & -2.6 & 118 & 0.0101 & 85 & 35 & 3.2999 & 3.068492 & 1.1565 & 0.6472 \\
\hline
\end{tabular}




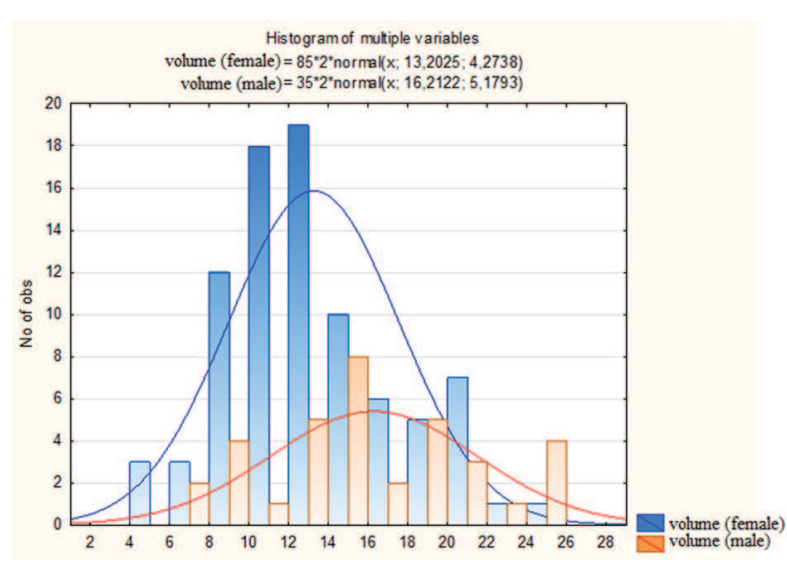

Fig. 10. A histogram demonstrating the comparison of volume values of the maxillary sinus across genders

contiguous teeth and patients with edentulous distal regions of the maxilla (Figures 11-13).

\section{Volumetric measurement of the maxillary sinus (measured in $\mathrm{cm}^{3}$ )}

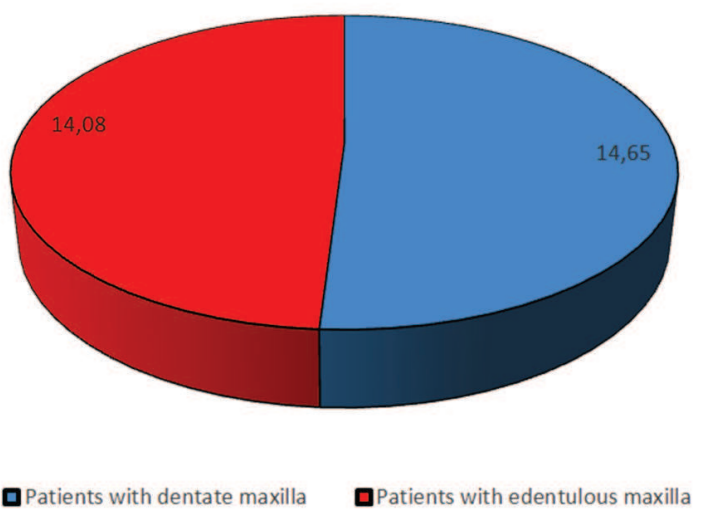

Fig. 12. Volumetric measurement of the maxillary sinus

Tabl. 4. A significant volume difference in male and female patients, the p-value being set at 0.0013 i.e. $<0.05$

\begin{tabular}{|c|c|c|c|c|c|c|c|c|c|c|c|}
\hline \multicolumn{12}{|c|}{$\begin{array}{l}\text { T-test for Independent Samples (GEORGIEV.sta) } \\
\text { Note: Variables were treated as independent samples }\end{array}$} \\
\hline & $\begin{array}{c}\text { Mean - } \\
\text { Group 1 }\end{array}$ & $\begin{array}{l}\text { Mean - } \\
\text { Group 2 }\end{array}$ & t-value & $\mathrm{df}$ & $\mathrm{p}$ & $\begin{array}{l}\text { Valid N - } \\
\text { Group } 1\end{array}$ & $\begin{array}{l}\text { Valid N } \\
\text { Group } 2\end{array}$ & $\begin{array}{l}- \text { Std.Dev. } \\
\text { Group } 1\end{array}$ & $\begin{array}{l}\text { Std.Dev. - } \\
\text { Group } 2\end{array}$ & $\begin{array}{c}\text { F-ratio - } \\
\text { Variances }\end{array}$ & $\begin{array}{c}\mathrm{p} \\
\text { - Variances }\end{array}$ \\
\hline $\begin{array}{l}\text { volume } \\
\text { (female) } \\
\text { vs. } \\
\text { volume (male) }\end{array}$ & 13.20 & 16.21 & -3.2 & 118 & 0.0013 & 85 & 35 & 4.27 & 5.18 & 1.46 & 0.16 \\
\hline
\end{tabular}

Comparison of maxillary sinus dimensions taken of dentate and edentulous posterior maxillas (measured in $\mathrm{mm}$ )

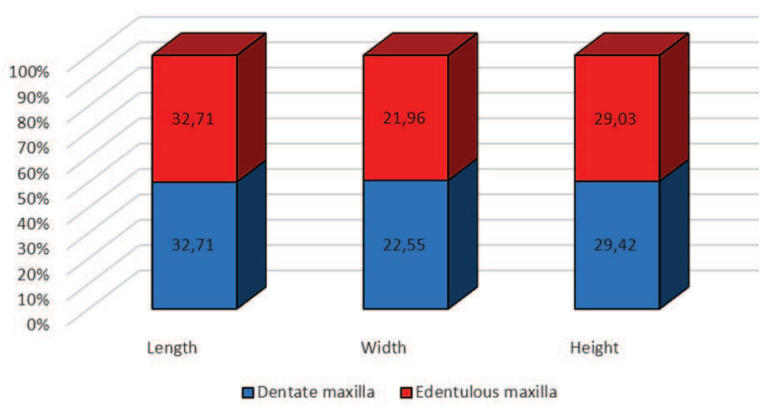

Fig. 11. Comparison of average dimensions (length, width and height) of the maxillary sinus for dentate and edentulous maxillas

\section{DISCUSSION}

Pneumatization of the maxillary sinus plays a crucial role in the decisions taken by the oral surgeon, performing a sinus floor augmentation proce-

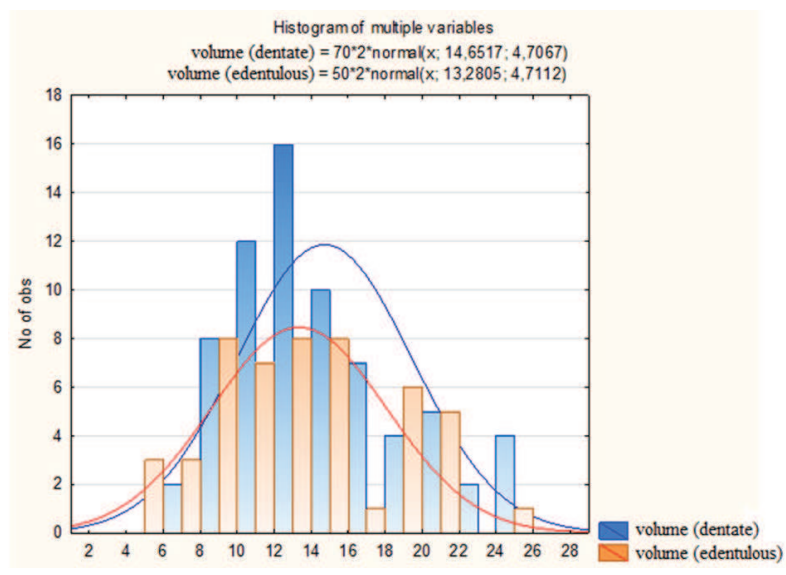

Fig. 13. A histogram demonstrating the comparison of volume values of the maxillary sinus for dentate and edentulous maxillas

dure, and the planning of the dental implant placement in the posterior maxilla. Dental literature reports various cases of maxillary sinus pneumatization following extraction of maxillary premolars and 
Tihomir Georgiev, Karen Djabalian, Radosveta Andreeva et al.

molars. Certain authors have witnessed a significant increase in the size of the maxillary sinus after tooth extraction or in edentulous jaws compared to dentate jaws $(10,11,12)$, whereas others have observed no correlation between the dental status and the volume of the maxillary sinus $(13,14)$. Sharah and Madjar (10) established that postextraction pneumatization occurred within the socket healing period of 4 to 6 months and after mature bone developed in the extraction socket, the pneumatization process was probably reduced to a minimum or ceased entirely.

Göçmen et al. (15) have examined the correlation of maxillary sinus pneumatization with the prevalence of nasal septal deviation, concha bullosa and Haller's cells. 300 CBCT scans (150 male, 150 female patients) from 2011 to 2014 were retrospectively reviewed for the presence of those anatomical variations. Data were analyzed with a Chi-square test. Results were as follows: $44.3 \%$ had concha bullosa, $37.3 \%$ nasal septal deviation, $19.3 \%$ Haller's cells and $27.7 \%$ maxillary sinus inferior pneumatization, which showed no correlation between the parameters under study.

Hamdy and Abdel-Wahed (16) have analyzed the maxillary sinus dimensions both linearly and volumetrically, using cone-beam computed tomography to assess the maxillary sinus pneumatization. Retrospective analysis of 30 maxillary sinuses belonging to 15 patients' CBCT scans revealed that the maximum craniocaudal extension of the maxillary sinus was located around the 2nd molar in $93 \%$ of the sinuses while the maximum mediolateral and antroposterior extensions of the maxillary sinus were located at the level of the root of the zygomatic complex in $90 \%$ of the sinuses.

Saccucci et al. (17) performed a study to determine whether sinus maxillary volumes could be related to a patient's gender. The maxillary sinus volumes of 52 patients (26 males and 26 females) with a mean age of 24.3 were calculated. No statistical difference was found in the patients' maxillary sinus volumes across genders.

Agacayak et al. (18) aimed to determine the effects of long-term oral breathing ( $>5$ years) of patients (over 21 years old) on the maxillary sinus volumes versus normal nasal breathing. The study involved a total of 239 male patients, of which 68 were oral breathers (Group 1) and 171 were nasal breathers (Group 2). The mean maxillary sinus volumes of Group 1 ranged 9043.49 \pm 1987.90 and of Group 2 varied $10851.77 \pm 2769.37$ - the difference in maxillary sinus volume between the 2 groups was statistically significant.

Tikku et al. (19) obtained results that strongly matched those of the previous study: mouth breathers showed lower maxillary sinus volume than normal nasal breathers $(p<0.05)$.

Lopes de Rezende Barbosa et al. (20) evaluated the maxillary sinus volume of patients with cleft lip and palate (unilateral and bilateral). The comparison was performed among 30 subjects with unilateral, 15 with bilateral cleft lip and palate and 15 control individuals (non-cleft) where each maxillary sinus was assessed three-dimensionally. No statistical differences were found when the groups were analyzed ( $>0.05$ ), with the unilateral cleft group presenting lower sinus volume than the other two groups.

Tolstunov (21) classified pneumatization of the maxillary sinus and its effects on implant treatment in the posterior maxilla, exploring $30 \mathrm{CBCT}$ scans and 60 panoramic images. The study presented the following results: SP0 (sinus pneumatization clear: not interfering with implant treatment in cases of high/small sinus), 2 sinuses or 3.3\%; SP1 (mild sinus enlargement), 29 sinuses or 48.3\%; SP2 (moderate SP), 16 sinuses or $26.7 \%$; SP3 (severe SP), 9 sinuses or $15.0 \%$; and SP4 (extreme), 4 sinuses or $6.7 \%$. Most analyzed maxillary sinuses ( 47 of 60 , or $78.3 \%$ ) were in the clear, mild, or moderate categories of sinus pneumatization, which had a sufficient amount of maxillary bone beneath the maxillary sinuses to allow a full-arch implant treatment.

There are rare conditions, unlike maxillary sinus pneumatization, such as maxillary sinus aplasia and hypoplasia, causing symptoms like headaches and voice alteration. The majority of the patients are asymptomatic, but these conditions must be determined because of the importance of the differential diagnosis such as infection and neoplasms. JafariPozve et al. (22) reported CBCT findings in three cases with maxillary sinus hypoplasia and aplasia.

Darsey et al. (23) carried out an interesting investigation of the effects orthodontic therapy of maxillary expansion with Hyrax appliance (rapid palatal 
expander) had on maxillary sinus volume. Examining CBCT images, belonging to 30 patients $(20 \mathrm{fe}-$ males, 10 males), taken before and after the treatment, the authors noted that Hyrax expansion therapy did not have a significant impact on maxillary sinus volume and the level of significance was inferior prior to and after treatment.

The present study, based on a special software application integrated in the CBCT scanner, facilitated the quick and easy estimate of the volume of the maxillary sinus, which has an irregular shape, and thus defies accurate mathematical calculation. Of the above-mentioned publications only Tolstunov (21) attempts to determine the degree of sinus pneumatization. However, measuring each and every sinus distance from the median line of the maxilla to the front wall of the maxillary sinus can be quite relative.

The volumetric assessment of the maxillary sinus and its pneumatization (primary or secondary) allows clinicians to accurately determine the exact site of surgical intervention and its anatomical variation. Maxillary sinus floor augmentation procedures with lateral access require precise location of the bone window as well as sufficiently wide sinus, so that elevation or removal could be adequate, judging the necessary amount of bone graft material to utilize.

Our findings do not show a significant difference in the volumetric measurements of maxillary sinuses of dentate and edentulous maxillas, which reinforces Sharah and Madjar's thesis of secondary postextraction pneumatization. The analysis of volumetric measurements of the maxillary sinuses across genders revealed statistically significant difference in favor of male patients.

\section{CONCLUSIONS}

$\mathrm{CBCT}$ imaging for surgical interventions of the maxillary sinus to assess its volume and size has proven to be an indispensable diagnostic tool. The measurement of the sinus volume and size can be evaluated easily and accurately. No significant difference between primary and secondary pneumatization was observed.

\section{REFERENCES}

1. Kilic C, Kamburoglu K, Yuksel SP, Ozen T. An assessment of the relationship between the maxillary sinus floor and the maxillary posterior teeth root tips using dental cone-beam computerized tomography. Eur J Dent 2010;4(4):462-7

2. Güven O. A clinical study on oroantral fistulae. J Cranio Maxillofac Surg 1998;26:267-71.

3. del Rey-Santamaria M, Valmaseda-Castellon E, Berini-Aytes L, Gay-Escoda C. Incidence of oral sinus communications in 389 upper third molar extraction. Med Oral Patol Oral Cir Bucal 2006;11, E334-8.

4. Jerome CE, Hill AV. Preventing root tip loss in the maxillary sinus during endodontic surgery. J Endod 1995;21:422-4.

5. Watzek G, Bernhart T, Ulm C. Complications of sinus perforations and their management in endodontics. Dent Clin North Am 1997;41:563-83.

6. Galindo-Moreno P, Padial-Molina M, Avila G, Rios HF, Hernández-Cortés P, Wang HL. Complications associated with implant migration into the maxillary sinus cavity. Clin Oral Implants Res. 2012 Oct;23(10):1152-60. doi: 10.1111/j.16000501.2011.02278.x. Epub 2011 Aug 15.

7. Felisati G, Lozza P, Chiapasco M, Borloni R. Endoscopic removal of an unusual foreign body in the sphenoid sinus: an oral implant. Clin Oral Implants Res. 2007 Dec;18(6):776-80. Epub 2007 Sep 14.

8. Griffa A, Viterbo S, Boffano P. Endoscopic-assisted removal of an intraorbital dislocated dental implant. Clin Oral Implants Res. 2010 Jul;21(7):77880. doi: 10.1111/j.1600-0501.2009.01894.x. Epub 2010 Apr 5.

9. Zijderveld SA, van den Bergh JP, Schulten EA, ten Bruggenkate $\mathrm{CM}$. Anatomical and surgical findings and complications in 100 consecutive maxillary sinus floor elevation procedures. J Oral Maxillofac Surg. 2008 Jul;66(7):1426-38. doi: 10.1016/j. joms.2008.01.027.

10. Sharan A, Madjar D. Maxillary sinus pneumatization following extractions: a radiographic study. Int J Oral Maxillofac Implants. 2008 Jan-Feb;23(1):48-56.

11. Harorh A, Bocutoğlu O. The comparison of vertical height and width of maxillary sinus by means of Waters' view radiograms taken from dentate and edentulous cases. Ann Dent. 1995 Summer-Fall;54(1-2):47-9.

12. Ohba $T$, Langlais RP, Morimoto $Y$, Tanaka $T$, Hashimoto K. Maxillary sinus floor in edentu- 
Tihomir Georgiev, Karen Djabalian, Radosveta Andreeva et al.

lous and dentate patients. Indian J Dent Res. 2001 Jul-Sep;12(3):121-5.

13. Ariji Y, Kuroki T, Moriguchi S, Ariji E, Kanda S. Age changes in the volume of the human maxillary sinus: a study using computed tomography. Dentomaxillofac Radiol. 1994 Aug;23(3):163-8.

14. Ariji Y, Ariji E, Yoshiura K, Kanda S. Computed tomographic indices for maxillary sinus size in comparison with the sinus volume. Dentomaxillofac Radiol. 1996 Jan;25(1):19-24.

15. Göçmen G, Borahan MO, Aktop S, Dumlu A, Pekiner FN, Göker K. Effect of Septal Deviation, Concha Bullosa and Haller's Cell on Maxillary Sinus's Inferior Pneumatization; a Retrospective Study. Open Dent J. 2015 Jul 31;9:282-6. doi: 10.2174/1874210601509010282. eCollection 2015.

16. Hamdy RM, Abdel-Wahed N. Three-dimensional linear and volumetric analysis of maxillary sinus pneumatization. J Adv Res. 2014 May;5(3):387-95. doi: 10.1016/j.jare.2013.06.006. Epub 2013 Jun 20.

17. Saccucci M, Cipriani F, Carderi S, Di Carlo G, D'Attilio M, Rodolfino D, Festa F, Polimeni A. Gender assessment through three-dimensional analysis of maxillary sinuses by means of cone beam computed tomography. Eur Rev Med Pharmacol Sci. 2015;19(2):185-93.

18. Agacayak KS, Gulsun B, Koparal M, Atalay Y, Aksoy $\mathrm{O}$, Adiguzel O. Alterations in maxillary sinus volume among oral and nasal breathers. Med Sci Monit. 2015 Jan 2;21:18-26. doi: 10.12659/ MSM.891371.

19. Tikku T, Khanna R, Sachan K, Srivastava K, Munjal N. Dimensional changes in maxillary sinus of mouth breathers. J Oral Biol Craniofac Res. 2013 Jan-Apr;3(1):9-14. doi: 10.1016/j.jobcr.2012.11.005. Epub 2012 Dec 1.

20. Lopes de Rezende Barbosa G, Pimenta LA, Pretti H, Golden BA, Roberts J, Drake AF. Difference in maxillary sinus volumes of patients with cleft lip and palate. Int J Pediatr Otorhinolaryngol. 2014 Dec;78(12):2234-6. doi: 10.1016/j.ijporl.2014.10.019. Epub 2014 Oct 25.

21. Tolstunov L, Thai D, Arellano L. Implant-guided volumetric analysis of edentulous maxillary bone with cone-beam computerized tomography scan. Maxillary sinus pneumatization classification. J Oral Implantol. 2012 Aug;38(4):377-90. doi: 10.1563/AAID-JOI-D-11-00212.
22. Jafari-Pozve N, Sheikhi M, Ataie-Khorasgani M, Jafari-Pozve S. Aplasia and hypoplasia of the maxillary sinus: A case series. Dent Res J (Isfahan). 2014 Sep;11(5):615-7.

23. Darsey DM, English JD, Kau CH, Ellis RK, Akyalcin S. Does hyrax expansion therapy affect maxillary sinus volume? A cone-beam computed tomography report. Imaging Sci Dent. 2012 Jun;42(2):838. doi: 10.5624/isd.2012.42.2.83. Epub 2012 Jun 25.

24. R. Shindjalova, K. Prodanova, V. Svechtarov, Modeling Data for Tilted Implants in Grafted with BioOss Maxillary Sinuses Using Logistic Regression, AIP Conference Proceedings, vol. 1631, pp. 58-62, 2014. 